\title{
Diablotexto
}

\section{Ana María Matute. Censura y autocensura: la (no) recuperación de su producción literaria}

Ana María Matute. Censorship and self-censorship: the (non) recovery of her literary production

\section{ESTEFANÍA LINUESA TORRIJOS \\ UNIVERSITAT DE VALÈNCIA}

Resumen: Este artículo pone el foco en la censura franquista y sus efectos en la obra de Ana María Matute. La literatura española de posguerra se vio condicionada por la censura editorial que implantó el régimen franquista, mas también por la autocensura de los editores y las escritoras, quienes la aplicaron por precaución, convirtiéndose, de esta manera, en sus propias censoras. En este sentido, Ana María Matute fue una de las escritoras que sufrió los efectos de la (auto)censura. En este artículo se analizarán tres obras de la escritora para comprobar si la incidencia y perpetuación de la (auto)censura se sigue reproduciendo en las últimas ediciones publicadas.

Palabras clave: Censura, Autocensura, Escritoras, Ana María Matute

Abstract: This article focuses on Franco's censorship and its effects on the work of Ana María Matute. Post-war Spanish literature was conditioned by the editorial censorship imposed by Franco's regime, but also by the self-censorship of publishers and writers, who applied it as a precaution, thus becoming their own censors. In this sense, Ana María Matute was one of the writers who suffered the effects of (self-) censorship. This article will analyse three of her works in order to check whether the incidence and perpetuation of (self-)censorship is still reproduced in the latest published editions.

Key words: Censorship, Self-censorship, Women writers, Ana María Matute 


\section{Introducción}

En España, la producción literaria del siglo XX estuvo marcada por la censura implantada por el régimen franquista. La censura editorial condicionó las corrientes literarias que surgieron durante la dictadura y, por extensión, la memoria cultural que hemos recibido.

El interés por nuestro pasado más reciente y, en concreto, por la dictadura franquista y sus consecuencias, es muy notable y axial en el ámbito de los estudios sobre la memoria en España. Dentro del ámbito de la recuperación de la memoria del franquismo, en este artículo nos centraremos en la vía que ofrece la literatura como mecanismo de transmisión de nuestra memoria cultural, para tratar de restaurar parte de esa memoria modificada y hasta silenciada. Para ello, examinaremos la transmisión cultural en obras literarias que, al estar censuradas, vinieron a coaccionar cuanto nos fue transmitido; sobre todo, cuando las obras no se (re)editaron respetando la voluntad última de los autores.

Ana María Matute fue una de las escritoras de la Generación de los 50 que sufrió los efectos de la (auto)censura. Una incidencia censora que se perpetúa hasta nuestros días. Para justificarlo, compararemos las galeradas de Los Abel (1948) y Los hijos muertos (1958) que se conservan en el Archivo General de la Administración con la última versión publicada a cargo de la editorial Planeta en 2014 y 2016 para corroborar cómo la censura y la autocensura siguen estando vigentes en las nuevas ediciones. Asimismo, analizaremos el caso de Luciérnagas (1993).

La censura editorial tuvo un papel fundamental en la reeducación de la población española. La producción cultural bajo el control censorio se convirtió en un instrumento de adoctrinamiento de la sociedad española1; por este motivo los censores controlaban todo aquello que salía a la luz y tomaron el control para decidir qué podía ser publicado. A través de la práctica censoria:

\footnotetext{
1 "En los años azules y autárquicos el control venía acompañado de la idea del libro como idea doctrinal y formación ideológica de los supuestos del Nuevo Estado. [...] En los primeros años, el libro era entendido no sólo [sic] como mercancía, sino como valor espiritual para los ideales del Nuevo Estado y su visión de política imperial y misión civilizadora [....]" (Martínez, 2015: 3233).
} 
se pretendía encauzar la producción intelectual para tratar de evitar la supuesta perversión que el pensamiento democrático había inducido en los españoles y que, desde su óptica, había sido una de las causas que hicieron inevitable la guerra (Larraz, 2014: 23)

La literatura fue un fiel testigo de la historia, de los años de penuria, de hambre y de miseria, de aquella España dividida, de aquella mujer que volvió a verse relegada a un segundo plano. Como señala Larraz (2014: 14):

\begin{abstract}
Ningún escritor habría podido escribir ya como si el Estado no existiera, como si la España de 1940 fuera la misma de 1935 o como si la forma de gobierno fuera otra, porque su presencia es constante y tiene vocación expresa de intervenir activamente en la vida cultural del país.
\end{abstract}

La censura del régimen franquista se originó en plena guerra $\mathrm{civil}^{2}$. Sin embargo, a pesar de la creación de un organismo encargado de la tarea de censura, de haber aprobado una legislación y de contar con los informes de censura - donde había unas preguntas que los lectores-censores debían responder ${ }^{3}$-, no hubo rigor a la hora de censurar la producción literaria, no hubo unos criterios o normas fijas a las cuales los escritores y lectores pudieran acogerse y regir sus expedientes. Este hecho hizo que la arbitrariedad de los lectores se impusiera en los informes de censura, y así lo manifestó Ana María Matute:

Los criterios, jamás los he llegado a conocer y siempre me han parecido contradictorios y arbitrarios. Y he llegado a suponer si tal confusión no obedecía al talante, idiosincrasia o humor circunstancial del individuo a quien tocara en suerte de censurar un manuscrito. Otra explicación no me alcanza. (citado en Abellán, 1980: 93)

Los escritores y escritoras a la hora de concebir su obra tenían presente que no escribían para el público, sino que en primera instancia lo hacían para el censor. Por este motivo, para evitar futuros problemas se negaban a sí mismos, medían sus palabras, suprimían pasajes, modificaban personajes...

\footnotetext{
2 "La política de Comunicación que nace el 18 de Julio de 1936 va unida al Bando de declaración de estado de guerra: se establece en él la previa censura y se determina que para someterse a ella deberán enviarse a la autoridad militar dos ejemplares de todos los impresos o documentos destinados a la publicidad" (Beneyto, 1987).

3 "¿Ataca al dogma? ¿A la mora? ¿A la Iglesia y a sus Ministros? ¿Al Régimen y a sus instituciones? ¿A las personas que colaboran o han colaborado con el Régimen? Los pasajes censurables, ¿califican el contenido de la obra?".
} 
La autocensura ${ }^{4}$ es el mayor éxito que tuvo el régimen franquista ya que facilitó la tarea de los censores y fueron los propios escritores los que aplicaron la tijera censora; además, confirió a esta práctica un peso más importante que a la propia censura ya que no solo afectaba a la novela sino también a la mente de los escritores.

Por otro lado, no debemos obviar la censura que ejercieron los editores, aunque se trate de un legado «invisible», ya que es muy complicado saber el impacto real que tuvieron en las novelas de la época. No obstante, sí que podemos saber gracias a testimonios de escritoras y escritores que en numerosas ocasiones fueron los editores los que, antes de presentar el libro a censura previa, hicieron recomendaciones a los autores sobre qué temas podían tocar o qué pasajes debían suprimir ${ }^{5}$. El siguiente fragmento ejemplifica el papel de los editores en la producción literaria del siglo XX. Se trata de una carta que José Vergés, editor de Destino, envió a García Badell:

Con respecto a la censura yo también creo que su libro no tiene nada de censurable en
cambio si [sic] creo que hay algunas frases absolutamente imprevisibles, ya que la
censura lo es por definición que podrían llegar a dar muchas molestias. Creo pues
sinceramente que es mejor que mandemos las pruebas a censura previa una vez
compuesto el libro. Creo que reflexionándolo bien será Vd. también de esta misma
opinión.
Carta de José Vergés a Gabriel García Badell fechada el 11 de enero de 1973. (citado
en Pueyo, 2021:50)

En suma, la literatura se vio sometida al lápiz rojo del censor para preservar la moral y tratar de enmudecer aquellas ideologías políticas contrarias al régimen. En el caso de las escritoras, la censura fue, en ocasiones, más rígida que la de sus compañeros ya que debían representar el papel de mujer sumisa, aunque muchas de ellas cruzaron esa barrera y reflejaron en su producción literaria un modelo de mujer antagónico a las ideas del régimen franquista. Por este motivo, es importante la inclusión de una perspectiva de género en el análisis de la censura durante la dictadura para visibilizar a las escritoras y poner de manifiesto el papel de la mujer de letras.

\footnotetext{
4 Entendemos por autocensura "la elección de temas y enfoques que un autor realiza para adecuar su escritura a las normas de un aparato de represión cultural y evitar que su texto sufra recortes, modificaciones o denegaciones de publicación" (Larraz, 2014: 33).

${ }^{5}$ Este tipo de censura tuvo mayor peso a partir de la Ley de prensa del 18 de marzo de 1966. La popularmente conocida como Ley Fraga suprimió la censura previa y se ofreció la posibilidad de presentar los textos a "consulta voluntaria".
} 


\section{Escritoras (auto)censuradas: Ana María Matute}

La dictadura reelaboró los conceptos que atañían a la mujer y se vio obligada a adaptarse al modelo de feminidad construido por el poder estatal. Desde el Estado se les dijo cómo debían pensar, vestir, en qué creer, cómo comportarse, cuándo y cuántos hijos debían tener, incluso, cómo hablar o moverse. En consecuencia, sufrieron la merma de libertades que se habían ido erigiendo, levemente, durante la Segunda República.

Dentro de este panorama desolador las escritoras tuvieron algunas dificultades para desenvolverse en un ambiente tan prohibitivo y censorio. Las escritoras en los años cuarenta y cincuenta tuvieron que abrirse paso en un mundo patriarcal y sufrieron la discriminación no solo de la censura sino también de sus compañeros de pluma.

Las escritoras de posguerra debían ceñirse a los patrones de religión y, por supuesto, conseguir pasar la censura, más estricta con las mujeres por el estilo de literatura que se esperaba de ellas. De esa forma, las escritoras de posguerra, así como todas las mujeres de aquella época, tenían unos límites marcados y estandarizados y debían atenerse a unos patrones de escritura que no eran muy distintos a los patrones sociales impuestos. Como explica Beatriz Sarlo en El imperio de los sentimientos (2000) la escritura femenina debía tratar un tema principalmente: el amor y el mundo de los sentimientos ${ }^{6}$.

Además de combatir o someterse al ángel del hogar como elemento censor femenino, cualquier régimen totalitario participa de ciertos filtros informativos que frenan cualquier posible subversión que pueda poner en riesgo el sistema establecido. Frente a este hecho tuvieron que combatir tanto hombres como mujeres que se desviaban de los márgenes establecidos por la dictadura. Sin embargo, existen dos filtros censorios más que únicamente la mujer escritora debía afrontar. Por un lado, la castración patriarcal que sufría la mujer a través de los patrones de conducta y el imaginario social impuesto

\footnotetext{
${ }^{6}$ Se trata de una historia sencilla que va desde el flechazo hasta el rechazo o la consumación del amor. Dada la trasgresión de la posible consumación del amor, el orden patriarcal se restaura de dos modos o bien mediante el matrimonio, o bien con la muerte de alguno de los amantes como castigo divino por sus actos (Sarlo, 2000).
} 
tanto por la dictadura como por la Falange y la Sección Femenina. Y, por otro lado, la censura religiosa que también actuaba como organismo represivo sobre la fisonomía y el pensamiento femenino. Por este motivo, las novelas que menos trabas tenían en la censura eran las que se englobaban en el género de la novela rosa. Sin embargo, un amplio elenco de autoras se incorporó a los movimientos renovadores y, siendo realmente subversivas, contravinieron los cánones y desafiaron los límites de ese modelo de mujer y de "los esquemas convencionales del género rosa" (Montejo, 2010: 77).

Muchas de estas escritoras fueron galardonadas o quedaron finalistas de prestigiosos premios literarios, como el Nadal, Ciudad de Barcelona o Planeta, que les brindaron la oportunidad de incorporarse a la narrativa española de los años cuarenta, cincuenta y sesenta. De este modo, podemos encontrar una amplia nómina de escritoras entre las que se encuentran Carmen Laforet, Carmen Martín Gaite, Dolores Medio, Eulalia Galvarriato, Elena Soriano, Carmen Kurtz, Mercedes Formica o, la que en estas líneas nos ocupa, Ana María Matute.

Ana María Matute pertenece a la llamada Generación de los 50, también conocida como "niños de la Guerra" o "niños asombrados"7, una generación que vivió la guerra civil desde una perspectiva infantil o adolescente y les marcó profundamente en su vida. Por eso, las tres novelas que aquí nos ocupan - Luciérnagas (1993), Los Abel (1948) y Los hijos muertos (1954) tienen como trasfondo literario el conflicto bélico y la posguerra, ahondando en las consecuencias sociales y las relaciones interpersonales.

Las escritoras de la Generación de los 50 reflejaron el momento histórico convirtiéndolo en memoria, una memoria en palabras de Tortosa (2014: 71) "personal y social de la grisácea postguerra que les toca vivir". Josefina Aldecoa reflejó en Los niños de la guerra (1983) cómo la infancia que les tocó vivir influyó en la producción literaria de todas ellas: "contamos lo que somos, lo que hemos hecho, para que los otros nos comprendan mejor y en

\footnotetext{
7 Josefina Aldecoa acuñó el término "niños de la guerra" para referirse a aquellos escritores que habían sufrido la Guerra Civil siendo unos niños. Ana María Matute, por su parte, se referiría a este grupo de escritores y escritoras como "niños asombrados" "por la perplejidad con que tuvieron que asumir la guerra civil y sus consecuencias justo en un momento crucial de su vida" (Sotelo, $2019: 12$ )
} 
consecuencia nos quieran más" (Aldecoa, 1983: 10). Y se convirtieron, de esta forma, en testigos directos y fieles. Estos "escritores testigos" como los denomina Santamaría:

pretendían explicar y explicarse el inmediato pasado, así como ofrecer una lección para el futuro. En los años cuarenta, cincuenta y sesenta, con el objetivo de que el recuerdo de la guerra no se borrara nunca, muchos escritores contaron la guerra con voluntad documental. (Santamaría, 2020: 29)

La producción literaria de Ana María Matute, desde un punto de vista ideológico bastante «neutral» tiene un mensaje de denuncia y protesta contra las injusticias sociales ya que según ella: "el oficio de escribir es también una forma de protesta. Protesta contra todo lo que representa opresión, fariseísmo e injusticia" (citado en Aldecoa, 1983: 226). Por ello, podemos considerar que estas novelas se enmarcan en la corriente del realismo social, aunque con un estilo propio.

Ana María Matute no se ciñó a escribir dentro de los límites establecidos por el régimen, sino que creó un universo literario comprometido con la época y con la situación de la mujer, por ello, los personajes femeninos tienen un lugar significativo dentro del mundo literario de Ana María Matute: Sol en Luciérnagas, Mónica en Los hijos muertos y Valba en Los Abel. Sus heroínas, siguiendo la corriente iniciada por Andrea en Nada (1945), transgreden la frontera del espacio doméstico y se adentran en un mundo asignado al hombre ${ }^{8}$. Son, por tanto, chicas "raras"9 que cuestionan el modelo femenino impulsado por el nacionalcatolicismo.

Los Abel abre el género literario de las novelas de aprendizaje femenino en la producción literaria de Ana María Matute. La protagonista, Valba, es una chica "rara" que no encarna el prototipo de mujer y lo podemos ver desde prácticamente el inicio de la novela cuando la joven recuerda estas palabras que un día le dijo su madre: "parece que seas un chico más, Valba. Quiero saber que tengo una niña[..]" (1948: 44). Tampoco se resigna a quedarse en

8 En Los Abel podemos observar cómo el espacio doméstico, la casa, se erige como un símbolo de soledad y tristeza.

9 "Chicas poco sociables o displicentes, que no se ponían a dar saltos de alegría cuando las invitaban a un "guateque», descuidaban su arreglo personal y se aburrían hablando de novios y de trapos" (Martín Gaite, 1994: 38) 
casa, sino que busca otro sitio más allá de ese espacio doméstico "no quiero envejecer aquí, no quiero arrastrar decadencias a lo largo de nuestra escalera de madera" (1948: 33), al igual que tampoco se doblega al matrimonio: "no voy a casarme con nadie, y menos aún con él” (1948: 215). Como vemos, esta chica "rara" no quiere imitar el modelo de mujer y rompe con el esquema social.

En suma, a través de la literatura y de la creación de sus heroínas Ana María Matute reivindicó el papel de la mujer en la esfera pública, la posibilidad de poder construir su identidad propia y dio voz a todas aquellas mujeres incomprendidas por la sociedad. En una época en la que la censura marcaba todo cuanto debía ser leído, las chicas "raras" se convirtieron en el espejo de muchas mujeres.

\section{El devenir de Luciérnagas (1993)}

En 1949 Ana María Matute concurrió al premio Nadal con Luciérnagas, pero quedó eliminada en la votación final ante la imposibilidad de poder publicarla (Soldevila, 1967: 98). No hay en el AGA ningún rastro de esta primera versión de la novela por lo que es muy probable que el editor de Destino hiciera una consulta extraoficial para ver la viabilidad de poder editarla.

Unos años más tarde, el 20 de octubre de 1953, Ramón Eugenio de Goicoechea presentó a censura previa una versión de Luciérnagas y se le asignó el Expediente 6147-53 ${ }^{10}$. El lector encargado de revisar la obra no concedió el permiso para su publicación por no ceñirse a la moral católica del régimen. En el expediente podemos leer como el censor manifiesta que:

Domina un total sentimiento antirreligioso que llega a la irreverencia en muchos pasajes. Jamás se cita un nombre santo [...] Políticamente, la novela deja mucho que desear. [...] El lector que suscribe opina que no debe autorizarse la obra, pues, intrínsecamente, resulta destructora de los valores humanos y religiosos esenciales. (AGA 21/10494)

En 1955 Ana María Matute había hecho cambios tan significativos - en palabras de la propia autora- que la llevaron a cambiar el nombre por En esta tierra (1955):

${ }^{10}$ AGA Sign. 21/0494 Exp. 6147-53. 
La censura me había tachado el manuscrito casi por completo. Lo cambié todo como pude y lo publicó Editorial Éxito. Por eso le cambié el título por el de En esta tierra. No quise que se llamara igual, porque no era la misma novela que había escrito. Para mí, En esta tierra siempre fue el título maldito de un libro que tuve que publicar por necesidad (Gazarian-Gautier, 1997:91).

Si cotejamos las galeradas de Luciérnagas $(1953)^{11}$ que se conservan en el Archivo General de la Administración del Estado (AGA) con la novela En esta tierra (1955) $)^{12}$ y Luciérnagas (1993) nos llama la atención que, a priori, los cambios entre En esta Tierra y Luciérnagas (1993) no son tan significativos como habría de suponer el lector ya que hay bastantes similitudes entre las dos versiones. A continuación, reproducimos algunos fragmentos para dar cuenta de las similitudes y diferencias que podemos encontrar en las tres versiones de la novela.

En primer lugar, la (auto)censura que se puede ver en estos fragmentos está relacionada con el tema de la religión. Como podemos observar, en los dos primeros fragmentos la autora añade citas del Deuteronomio; en el último observamos cómo Matute decidió suprimir una frase que iría en contra del dogma católico, que no recuperó en la última versión.

\begin{tabular}{|c|c|c|}
\hline LUCIÉRNAGAS (1953) & EN ESTA TIERRA (1955) & LUCIÉRNAGAS (1993) \\
\hline $\begin{array}{l}\text { Leía su Biblia, leía a } \\
\text { Kropotkine }^{13}, \\
\text { recordaba, } \\
\text { (Mecantentaba, recreaba... }\end{array}$ & $\begin{array}{l}\text { Leía su Biblia. Alucinando, } \\
\text { como un actor loco, paseaba } \\
\text { por su pobre habitación, } \\
\text { pobre, tristísima, } \\
\text { leyendo:...Y Yahvé le mostró } \\
\text { toda la tierra de Galaad } \\
\text { hasta Dan, todo Neftalé, la } \\
\text { Tierra de Efraim y Manasés, } \\
\text { y toda la tierra de Judá hasta } \\
\text { el mar último, el Negueb, la } \\
\text { llanura, la vega de Jericó, } \\
\text { ciudad de las palmeras, } \\
\text { hasta Soar... Ésta es la tierra } \\
\text { por la cual juré a } \\
\text { Abraham....Leía a Kropoktine, } \\
\text { intentaba, recordaba, }\end{array}$ & $\begin{array}{l}\text { Leía su Biblia. Alucinado, } \\
\text { como un actor loco, paseaba } \\
\text { por su pobre habitación, } \\
\text { leyendo: “... Y Yahvé le } \\
\text { mostró toda la tierra de } \\
\text { Galaad hasta Dan, todo } \\
\text { Neftalé la tierra de Efraim y } \\
\text { Manasés, y toda la tierra de } \\
\text { Judá hasta el mar último; el } \\
\text { Negueb, la llanura, la vega } \\
\text { de Jericó, ciudad de las } \\
\text { palmeras, hasta Soar... Esta } \\
\text { es la tierra por la cual juré a } \\
\text { Abraham...”. Leía a } \\
\text { Kropotkine, inventaba, } \\
\text { recordaba, recordaba, }\end{array}$ \\
\hline
\end{tabular}

11 AGA Sign. 21/10494 Exp. 6147-53.

12 AGA Sign. 21/11093 Exp. 2687-55.

13 Piotr Alekséyevich Kropotkin (1842-1921) fue un escritor y pensador anarquista ruso. Entre sus obras podemos destacar La conquista del pan (1892), Memorias de un revolucionario (1899), La moral Anarquista (1907), entre otras. 


\begin{tabular}{|c|c|c|}
\hline & $\begin{array}{ll}\text { recreada... } & \text { (Mecanuscrito: } \\
186) & \end{array}$ & recreaba... (2019: 286) \\
\hline $\begin{array}{l}\text { Hasta en el momento de la } \\
\text { victoria estaba solo. En el } \\
\text { vacío errante como una } \\
\text { estrella que cae, que siempre } \\
\text { cae, que siempre cae, sin ruta } \\
\text { ni destino. (Mecanuscrito: 209) }\end{array}$ & $\begin{array}{l}\text { En el minuto de la victoria } \\
\text { estaba solo, en el vacío como } \\
\text { una estrella que cae, que } \\
\text { siempre cae, sin lograr el } \\
\text { destino. "Sube a la cumbre } \\
\text { del Pisgá, y alza los ojos } \\
\text { hacia el poniente, el } \\
\text { septentrión, el sur y el } \\
\text { oriente, y contempla con tus } \\
\text { ojos, pues no has de pasar } \\
\text { este Jordán." (Mecanuscrito: } \\
\text { 199) }\end{array}$ & $\begin{array}{l}\text { En el mundo de la victoria } \\
\text { estaba solo como una estrella } \\
\text { que cae, que siempre cae, sin } \\
\text { lograr el destino. "Sube a la } \\
\text { cumbre del Pisgá, y alza los } \\
\text { ojos hacia el poniente, el } \\
\text { septentrión, el sur y el } \\
\text { oriente, y contempla con tus } \\
\text { ojos, pues no has de pasar } \\
\text { este Jordán". (2019: 298) }\end{array}$ \\
\hline $\begin{array}{l}\text { Trataba tal vez de justificarse } \\
\text { ante su conciencia. A ellos } \\
\text { dos, a su bochornosa juventud. } \\
\text { Podría incluso ser mas [sic] } \\
\text { sincero recomendando en } \\
\text { vez de fe, el pillaje, el } \\
\text { suicidio. ¿Por qué quería } \\
\text { engañar en el último } \\
\text { momento? El [sic] iba a morir, } \\
\text { era seguro. (Mecanuscrito: } \\
\text { 253) }\end{array}$ & $\begin{array}{l}\text { Trataba tal vez de justificarse } \\
\text { ante su conciencia, apelando a } \\
\text { ellos dos, a su juventud. ¿Por } \\
\text { qué se quería engañar también } \\
\text { en su último momento? Iba a } \\
\text { morir, era seguro. } \\
\text { (Mecanuscrito: } 225 \text { ) }\end{array}$ & $\begin{array}{l}\text { Tuvo una súbita piedad por } \\
\text { Pablo, le pareció que estaba } \\
\text { pidiéndoles algo a ellos dos, a } \\
\text { su juventud. ¿Por qué se } \\
\text { quería engañar también en su } \\
\text { última hora? Iba a morir, era } \\
\text { seguro. (2019: 324) }\end{array}$ \\
\hline
\end{tabular}

Ana María Matute tampoco recuperó en la versión de Luciérnagas los pasajes en los que se cuestiona la educación que recibió la protagonista, como podemos ver a continuación:

\begin{tabular}{|c|c|c|}
\hline LUCIÉRNAGAS (1953) & EN ESTA TIERRA (1955) & LUCIÉRNAGAS (1993) \\
\hline $\begin{array}{l}\text { [...] le sorprendió escondiendo } \\
\text { un grueso libro de tapas rojas. } \\
\text { La miró con ojos } \\
\text { amenazadores, amo } \\
\text { advirtiéndole que era mejor no } \\
\text { decir ni preguntar nada. Sol } \\
\text { salió en silencio, } \\
\text { experimentando un débil } \\
\text { desprecio, porque suponía que } \\
\text { su hermano también leía } \\
\text { aquellos librotes pornográficos } \\
\text { que en Saint-Paul }{ }^{14} \text { corrían de } \\
\text { mano en mano, } \\
\text { clandestinamente. }\end{array}$ & $\begin{array}{l}\text { [...] le vio esconder un grueso } \\
\text { libro de tapas rojas. Sol, para } \\
\text { no molestarle, salió en silencio, } \\
\text { experimentando un débil } \\
\text { desprecio, suponiendo que leía } \\
\text { algún librote pornográfico de } \\
\text { los que se exhibían } \\
\text { profusamente en los quioscos } \\
\text { de las } \\
\text { (Mecanuscrito: } 20)\end{array}$ & $\begin{array}{l}\text { [...] le vio esconder un grueso } \\
\text { libro de tapas rojas. Sol, para } \\
\text { no molestarle, salió en silencio, } \\
\text { experimentando un débil } \\
\text { desprecio, suponiendo que leía } \\
\text { algún librote pornográfico de } \\
\text { los que se exhibían } \\
\text { profusamente en los quioscos } \\
\text { de las Ramblas. (2019: 119) }\end{array}$ \\
\hline
\end{tabular}

${ }^{14}$ Saint-Paul es el colegio religioso dirigido por monjas al que acude la protagonista, Sol. 


\begin{tabular}{|c|c|c|}
\hline (Mecanuscrito: 15) & & \\
\hline $\begin{array}{l}\text { Bruscamente, recayeron } \\
\text { sobre ella los nueve años de } \\
\text { Saint-Paul, con todos sus } \\
\text { prejuicios inútiles, sus } \\
\text { enseñanzas inútiles. Vino a } \\
\text { su imaginación el recuerdo de } \\
\text { aquel tomo de Catecismo, del } \\
\text { Padre Ripalda, aquel librito } \\
\text { menudo de sus años párvulos, } \\
\text { con sus grabados primarios. } \\
\text { (Mecanuscrito: } 232 \text { ) }\end{array}$ & $\begin{array}{l}\text { De repente recordó el tomito } \\
\text { de Catecismo, del Padre } \\
\text { Ripalda, con sus grabados } \\
\text { primarios. (Mecanuscrito: } 232 \text { ) }\end{array}$ & $\begin{array}{l}\text { Y recordó el tomito de } \\
\text { Catecismo del padre Ripalda, } \\
\text { con sus grabados. (2019: } 308)\end{array}$ \\
\hline
\end{tabular}

Sin embargo, podemos ver fragmentos donde presuponemos que la autora se autocensuró y en la versión de 1993 decidió despojarse de ellos, como podemos ver en el siguiente pasaje:

"Se acababa el colegio, las lecciones mal aprendidas, el olor a las monjas" (Mecanuscrito: 2) frente a "Se acababa el colegio, las lecciones mal aprendidas, la severa disciplina de las monjas" (2019: 106).

Del mismo modo, también están presentes los cambios que tienen que ver con la representación de la Guerra Civil en la trama. Las alteraciones afectan a la descripción de personajes - como los dos primeros - y a la descripción de situaciones -el último fragmento -. En la primera versión de Luciérnagas el narrador muestra una visión más objetiva de la guerra y no se adscribe a ningún bando, sin embargo, este hecho cambia en En esta tierra. En el primer fragmento podemos ver cómo se otorga una connotación negativa a la revolución; y, por el contrario, se ofrece una visión en consonancia con el propagandismo ideológico de la contienda bélica refiriéndose al ejército sublevado como el "Ejército Nacional"; de igual manera, alude a los aviones que sobrevuelan la "ciudad roja" como un símbolo de "libertad". De esta forma, podemos ver cómo la autora practica la autocensura para que el lector encargado del informe le conceda la autorización ${ }^{15}$.

\footnotetext{
15 Estruch Tobella también señaló en su artículo Las tres versiones de Luciérnagas alteraciones destinadas a cambiar la orientación política.
} 


\begin{tabular}{|c|c|c|}
\hline LUCIÉRNAGAS (1953) & EN ESTA TIERRA (1955) & LUCIÉRNAGAS (1993) \\
\hline $\begin{array}{l}\text { Entonces, la seguía gritaba lo } \\
\text { que ellos y, como ellos, } \\
\text { levantaba el puño. De este } \\
\text { modo, un mundo desquiciado, } \\
\text { nuevo, se abría ante sus ojos. } \\
\text { Poco a poco, se veía impelido } \\
\text { hacia aquellos seres. Hacia } \\
\text { aquel colectivo "dejarse llevar } \\
\text { ", hacia aquel inconsciente vivir } \\
\text { al día, que le agradaba. } \\
\text { (Mecanuscrito: } 78 \text { ) }\end{array}$ & $\begin{array}{l}\text { Entonces, gritaba como ellos, } \\
\text { gritaba y levantaba el puño, sin } \\
\text { saber mucho más el porqué, } \\
\text { llevado de la sugestión } \\
\text { mimética de lo colectivo. De } \\
\text { este modo, un mundo nuevo, } \\
\text { desquiciado, se abría ante sus } \\
\text { ojos. Poco a poco se veía } \\
\text { impelido hacia aquellos seres, } \\
\text { hacia el fácil "dejarse llevar", } \\
\text { comunitario, suprema y } \\
\text { aborregada aspiración de las } \\
\text { masas democráticas, hacia } \\
\text { aquel inconsciente vivir al día } \\
\text { que le agradaba, como a todo } \\
\text { ser débil, por cómodo. } \\
\text { (Mecanuscrito: 78) }\end{array}$ & $\begin{array}{l}\text { Entonces, gritaba como ellos, } \\
\text { gritaba y levantaba el puño, sin } \\
\text { saber del todo el porqué. } \\
(2019: 177)\end{array}$ \\
\hline $\begin{array}{l}\text { La ciudad parecía revolverse } \\
\text { en un último estertor. En las } \\
\text { calles se advertía una huida } \\
\text { presurosa y angustiada, mal } \\
\text { velada. [...] Oyó entonces } \\
\text { algún comentario, referente al } \\
\text { Ejército que se aproximaba a } \\
\text { la ciudad. (Mecanuscrito: } 302 \text { ) }\end{array}$ & $\begin{array}{l}\text { La ciudad roja se revolvía en } \\
\text { su último estertor. Los } \\
\text { republicanos huían presurosos } \\
\text { ante el avance del Ejército } \\
\text { Nacional, y en las calles se } \\
\text { palpaba el miedo y la angustia, } \\
\text { mal velada. [...] Franco } \\
\text { avanzaba, avanzaba. [...] Oyó, } \\
\text { con curiosidad, algún } \\
\text { comentario, aún acalorado, } \\
\text { receloso, referente a los } \\
\text { Nacionales, cada día más } \\
\text { próximos. (Mecanuscrito: 266) }\end{array}$ & $\begin{array}{l}\text { La ciudad se revolvía como en } \\
\text { un último estertor, las gentes } \\
\text { huían presurosas ante el } \\
\text { avance del ejército de Franco, } \\
\text { y en las calles se palpaba la } \\
\text { pena y la angustia, mal } \\
\text { veladas. [...] Franco avanzaba, } \\
\text { avanzaba. [...] y oía algún } \\
\text { comentario, aún acalorado, } \\
\text { receloso, referente a los que } \\
\text { avanzaban, cada vez más } \\
\text { próximos. (2019:364-365) }\end{array}$ \\
\hline $\begin{array}{l}\text { Los aviones volaban cada vez } \\
\text { más bajo, como bandas en } \\
\text { acecho. (Mecanuscrito: } 345 \text { ) }\end{array}$ & $\begin{array}{l}\text { Los aviones volaban cada vez } \\
\text { más bajo, como un anuncio de } \\
\text { la inminente libertad. } \\
\text { (Mecanuscrito: } 286 \text { ) }\end{array}$ & $\begin{array}{l}\text { Los aviones volaban cada vez } \\
\text { más bajo. (2019: } 382)\end{array}$ \\
\hline
\end{tabular}

En definitiva, podemos ver cómo las tres versiones de Luciérnagas guardan bastantes similitudes entre ellas y más que la recuperación de "la primitiva versión" tenemos una reescritura de la novela, con un estilo mucho más cuidado. Si bien es cierto que se suprimen algunos fragmentos añadidos a la versión de En esta tierra, otras veces la autora opta por conservarlos. Del mismo modo, tal y como hemos evidenciado, hay fragmentos que fueron suprimidos de la primera versión y que Matute no recuperó en la versión de 1993. Por otro lado, tal y como señala Estruch, hay pasajes en los que "la primera y la segunda versión son casi idénticas" (2014: 2). Además, a estas 
tres versiones habría que sumar la versión que Ana María Matute presentó al Premio Nadal en 1949, pero, lamentablemente, es ilocalizable.

En suma, estamos ante una obra con tres versiones y, en nuestra opinión, es necesaria una edición crítica que englobe los tres textos y permita un estudio completo de Luciérnagas.

\section{La (no) recuperación de su producción literaria: Los Abel (1948) y Los} hijos muertos (1958)

Los Abel (1948) y Los hijos muertos (1958) son otras novelas de la autora que tuvieron que enfrentarse a la tijera censora. En primer lugar, analizaremos Los Abel. Para ello, nos hemos apoyado en las galeradas que se conservan en el AGA, en la primera edición publicada por Destino en 1948 y, por último, en la edición de 2015 en formato digital a cargo de la editorial Planeta. En segundo lugar, para el cotejo de Los hijos muertos nos hemos servido del texto que podemos consultar en el AGA, de la edición de José Mas y M. Teresa Mateu en la editorial Cátedra y, finalmente, de la edición en formato digital de 2015 de la editorial Planeta. Tras el cotejo de los diferentes textos hemos advertido que la censura que un día condicionó y coaccionó las novelas sigue reproduciéndose en las ediciones consultadas.

Los Abel fue presentada a censura por la editorial Destino el 12 de agosto de 1948 y se le asignó el expediente N. ${ }^{\circ}$ 4030-48 ${ }^{16}$. El lector a cargo del informe autorizó la publicación con las supresiones indicadas en las páginas 28, 29 y 33 por considerarse un ataque a la moral (AGA 21/08406). Como hemos comentado anteriormente, la mujer tenía que encarnar la moral católica.

En el primer fragmento observamos que la incidencia de la censura sigue estando vigente en la edición de 2015; además, la autora censura la frase anterior "luego encontré sus ojos, obsesionados por una idea fija" para evitar que en la revisión el censor decidiera suprimirla por insinuar una escena inmoral, un beso. Lo mismo sucede en el segundo fragmento censurado, que retrata una escena demasiado "erótica" para la moral del régimen franquista.

${ }^{16}$ AGA Sign. 21/08406 Exp. 4030-48. 
Las tachaduras hacen que el lector no comprenda bien el asombro de Eloy, que acaba de ser rechazado por Valba.

\begin{tabular}{|c|c|c|}
\hline EXPEDIENTE N. 4030-48 & PRIMERA EDICIÓN 1948 & $\begin{array}{l}\text { EDICIÓN FORMATO DIGITAL } \\
2015\end{array}$ \\
\hline 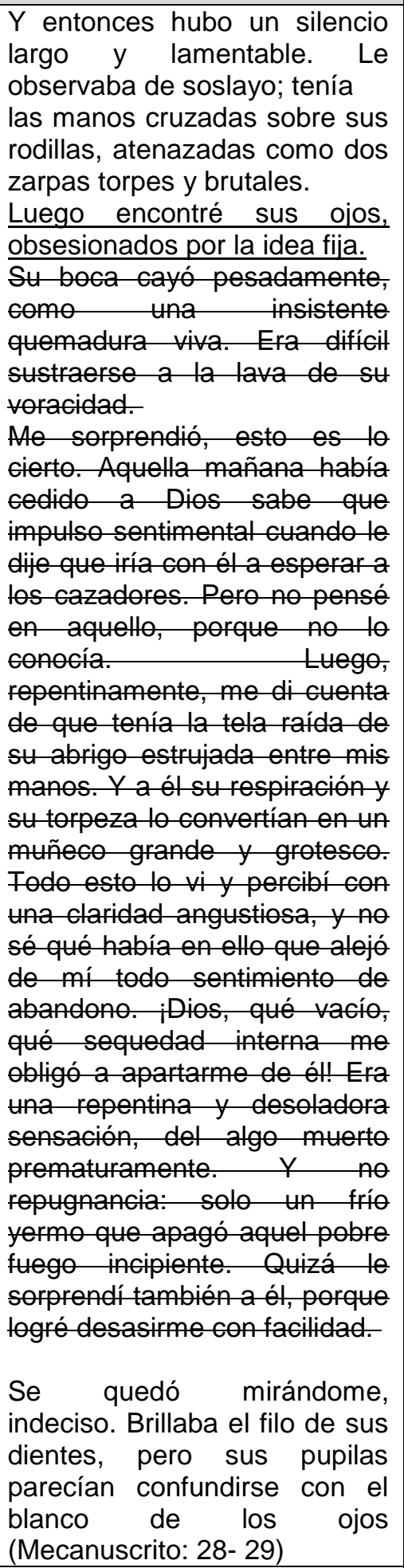 & $\begin{array}{l}\text { Y entonces hubo un silencio } \\
\text { largo y lamentable. Le } \\
\text { observaba de soslayo; tenía las } \\
\text { manos cruzadas sobre sus } \\
\text { rodillas, atenazadas como dos } \\
\text { zarpas torpes y brutales. } \\
\text { Se quedó mirándome, indeciso. } \\
\text { Brillaba el filo de sus dientes, } \\
\text { pero sus pupilas parecían } \\
\text { confundirse en el blanco de los } \\
\text { ojos. (p. 87) }\end{array}$ & $\begin{array}{l}\text { Y entonces hubo un silencio } \\
\text { largo y lamentable. Le } \\
\text { observaba de soslayo; tenía } \\
\text { las manos cruzadas sobre } \\
\text { sus rodillas, atenazadas } \\
\text { como dos zarpas torpes y } \\
\text { brutales. Se quedó } \\
\text { mirándome, indeciso. } \\
\text { Brillaba el filo de sus dientes, } \\
\text { pero sus pupilas parecían } \\
\text { confundirse en el blanco de } \\
\text { los ojos. }\end{array}$ \\
\hline Estaba demasiado próximo su & Estaba demasiado próximo su & Estaba demasiado $p$ \\
\hline
\end{tabular}




\begin{tabular}{|c|c|c|}
\hline $\begin{array}{l}\text { fuerza, su atroz y avasalladora } \\
\text { fuerza. Y me parecía que cada } \\
\text { beso suyo era un pedazo de } \\
\text { vida que le estaba robando, } \\
\text { segundos de su existencia, } \\
\text { que yo poseía ávidamente. } \\
\text { Era un rabioso chocar de } \\
\text { dientes, un abrazo cada vez } \\
\text { más innoble. Había allí un } \\
\text { poco amargo, ácido. } \\
\text { Despertaba en mílo que Eloy } \\
\text { hunca conseguiría nunca } \\
\text { satisfacer. Y lo sabía. Hasta } \\
\text { que, de improviso, sin } \\
\text { suavidad, otra vez me invadió } \\
\text { aquella desgarradora } \\
\text { impresión que me helaba la } \\
\text { sangre. (Mecanuscrito: } 33 \text { ) }\end{array}$ & $\begin{array}{l}\text { fuerza, su atroz y avasalladora } \\
\text { fuerza. Hasta que, de improviso, } \\
\text { sin suavidad, otra vez me } \\
\text { invadió aquella desgarradora } \\
\text { impresión que me helaba la } \\
\text { sangre. (p. 99) }\end{array}$ & $\begin{array}{l}\text { su fuerza, su atroz y } \\
\text { avasalladora fuerza. Hasta } \\
\text { que, de improviso, sin } \\
\text { suavidad, otra vez me } \\
\text { invadió aquella desgarradora } \\
\text { impresión que me helaba la } \\
\text { sangre. }\end{array}$ \\
\hline
\end{tabular}

Por otro lado, Los hijos muertos ${ }^{17}$ fue presentada a censura el 14 de mayo de 1958 por la editorial Planeta y, como veremos a continuación, la incidencia de la censura fue mayor que en Los Abel. Los hijos muertos pasó hasta por tres lectores diferentes: el primer lector fue el cura Miguel de la Pinta que autorizó su publicación. Sin embargo, esto no fue suficiente y se encargó un nuevo informe a dos lectores: Eznarriaga y Pablo Muñoz. Ambos tacharon numerosas palabras, en su mayoría malsonantes, como veremos a continuación. Eznarriaga propuso tachaduras en las páginas 30, 149, 150, 151, $192,248,293,296,497,500,577,612,625,633$ por ser un ataque a la moral y según él "podrian [sic] suprimirse o sustituirse por puntos suspensivos, pues aunque reflejan un modo de hablar corriente de los personajes no son imprescindibles". El último lector, Jose de Pablo Muñoz, señaló en su informe que "deben suprimirse las palabras subrayadas en las paginas [sic]: 184, 203, 204, 248, 257, 259, 261, 284, 285, 288, 290, 291, 298, 308, 323, 336, 429, 430, 625, 626" (AGA 21/11995)

En la siguiente tabla se puede apreciar que, al igual que en Los Abel, las palabras que un día el censor silenció siguen estando ausentes en las últimas versiones publicadas. 


\begin{tabular}{|c|c|c|}
\hline EXPEDIENTE N. ㅇ 2322-58 & EDICIÓN DIGITAL 2015 & $\begin{array}{c}\text { EDICIÓN CRÍTICA DE LA } \\
\text { EDITORIAL CÁTEDRA (2016) }\end{array}$ \\
\hline $\begin{array}{l}\text { Cuando en julio de } 1936 \\
\text { estalló la guerra civil tras unas } \\
\text { horas e incertidumbre, Negroz } \\
\text { quedó dentro de la zona } \\
\text { nacional. (Mecanuscrito: } 30 \text { ) }\end{array}$ & $\begin{array}{l}\text { Cuando en julio de } 1936 \\
\text { estalló la guerra, tras unas } \\
\text { horas de incertidumbre, los de } \\
\text { Hegroz vieron llegar por la } \\
\text { carretera algunos coches con } \\
\text { falangistas armados. }\end{array}$ & $\begin{array}{l}\text { Cuando en julio de } 1936 \\
\text { estalló la guerra, tras unas } \\
\text { horas de incertidumbre, los de } \\
\text { Hegroz vieron llegar por la } \\
\text { carretera algunos coches con } \\
\text { falangistas armados (2016: } \\
\text { 209) }\end{array}$ \\
\hline $\begin{array}{l}\text { La naranja que se comía la } \\
\text { puta, el limpiabotas, la corista } \\
\text { flaca, de regreso a la pensión. } \\
\text { (Mecanuscrito: 149) }\end{array}$ & $\begin{array}{l}\text { La naranja que se comía la } \\
\text { esquinera, el limpiabotas, la } \\
\text { corista flaca, de regreso a la } \\
\text { pensión }\end{array}$ & $\begin{array}{l}\text { La naranja que se comía la } \\
\text { esquinera, el limpiabotas, la } \\
\text { corista flaca, de regreso a la } \\
\text { pensión. (2016: 308) }\end{array}$ \\
\hline $\begin{array}{l}\text { Y aquellos que miró con más } \\
\text { curiosidad, estupefacto, desde } \\
\text { su primera inocencia: los } \\
\text { últimos de la noche, los } \\
\text { juerguistas que bajaban de la } \\
\text { ciudad alta, los señoritos con } \\
\text { la camisa sucia, los maricones } \\
\text { ricos, los pintores, los } \\
\text { intelectuales, turistas, rientes, } \\
\text { fatigados [...] (Mecanuscrito: } \\
\text { 150) }\end{array}$ & $\begin{array}{l}\text { Y aquellos que miró con más } \\
\text { curiosidad, estupefacto, desde } \\
\text { su primera inocencia: los } \\
\text { últimos de la noche, los } \\
\text { juerguistas que bajaban de la } \\
\text { ciudad alta, los «señoritos» } \\
\text { con la camisa sucia. Turistas, } \\
\text { rientes, fatigados [...] }\end{array}$ & $\begin{array}{l}\text { Y aquellos que miró con más } \\
\text { curiosidad, estupefacto, desde } \\
\text { su primera inocencia: los } \\
\text { últimos de la noche, los } \\
\text { juerguistas que bajaban de la } \\
\text { ciudad alta, los «señoritos» } \\
\text { con la camisa sucia. Turistas, } \\
\text { rientes, fatigados [...] (2016: } \\
\text { 309) }\end{array}$ \\
\hline $\begin{array}{l}\text { [...] sus guisos grasientos, su } \\
\text { blenorragia, sus pucheros, sus } \\
\text { legañas }[\ldots] \text { sus riñas, sus } \\
\text { coitos }[\ldots](1958: 151)\end{array}$ & $\begin{array}{l}\ldots] \text { sus guisos grasientos, sus } \\
\text { pucheros, sus legañas }[\ldots] \text { sus } \\
\text { riñas, sus partos }[\ldots]\end{array}$ & $\begin{array}{l}{[\ldots] \text { sus guisos grasientos, sus }} \\
\text { pucheros, sus legañas }[\ldots] \text { sus } \\
\text { riñas, sus partos [...] (2016: } \\
309)\end{array}$ \\
\hline $\begin{array}{l}\text { Seguía el calor, el sol impío y } \\
\text { central, cuando llegó un } \\
\text { hombre, de corta estatura, } \\
\text { nervioso, duro, Socialista, } \\
\text { exsuboficial de Regulares. } \\
\text { Venía enviado por López } \\
\text { Tienda }{ }^{18} \text {. En seguida le llamó a } \\
\text { su lado (Mecanuscrito: } 184 \text { ) }\end{array}$ & $\begin{array}{l}\text { Seguía el calor, el sol impío y } \\
\text { central, cuando llegó un } \\
\text { hombre, de corta estatura, } \\
\text { nervioso, duro, Socialista, } \\
\text { exsuboficial de Regulares. } \\
\text { Venía enviado por el capitán } \\
\text { Arcos. En seguida le llamó a } \\
\text { su lado. }\end{array}$ & $\begin{array}{l}\text { Seguía el calor, el sol impío y } \\
\text { central, cuando llegó un } \\
\text { hombre, de corta estatura, } \\
\text { nervioso, duro, Socialista, } \\
\text { exsuboficial de Regulares. } \\
\text { Venía enviado por el capitán } \\
\text { Arcos. En seguida le llamó a } \\
\text { su lado (2016: } 336)\end{array}$ \\
\hline $\begin{array}{l}\text { Ah, Isabel, ¿no fuiste tú la que } \\
\text { lo dijo, aquel día, con los } \\
\text { puños apretados, delante del } \\
\text { viejo? ¿No fuiste tú la que } \\
\text { dijiste: «iDeberíamos abrasarla } \\
\text { a ella con carbones } \\
\text { encendidos, y a él echarlo a la } \\
\text { nieve, descalzo, a latigazos, } \\
\text { como a un perro! iY que nunca } \\
\text { sepa más de ella!»?...¿ ¿No fue } \\
\text { Isabel Corvo, la cristiana, la }\end{array}$ & $\begin{array}{l}\text { Ah, Isabel, ¿no fuiste tú la que } \\
\text { lo dijo, aquel día, con los } \\
\text { puños apretados, delante del } \\
\text { viejo? ¿No fuiste tú la que } \\
\text { dijiste: « ¡Deberíamos abrasarla } \\
\text { a ella con carbones } \\
\text { encendidos, y a él echarlo a la } \\
\text { nieve, descalzo, a latigazos, } \\
\text { como a un perro! iY que nunca } \\
\text { sepa más de ella!»? La soltó y } \\
\text { se fue hacia la pared. }\end{array}$ & $\begin{array}{l}\text { Ah, Isabel, ¿no fuiste tú la que } \\
\text { lo dijo, aquel día, con los } \\
\text { puños apretados, delante del } \\
\text { viejo? ¿No fuiste tú la que } \\
\text { dijiste: «iDeberíamos abrasarla } \\
\text { a ella con carbones } \\
\text { encendidos, y a él echarlo a la } \\
\text { nieve, descalzo, a latigazos, } \\
\text { como a un perro! ¡Y que nunca } \\
\text { sepa más de ella!»? La soltó y } \\
\text { se fue hacia la pared (2016: }\end{array}$ \\
\hline
\end{tabular}

${ }^{18}$ La alusión al capitán López Tienda se suprime también en las páginas 203, 204 


\begin{tabular}{|c|c|c|}
\hline $\begin{array}{l}\text { justa, la intachable, quien dijo } \\
\text { eso? iPara ti no hay más que } \\
\text { una clase de pecado, Isabel } \\
\text { corvo, un pecado que tú no } \\
\text { has cometido! La soltó y se fue } \\
\text { hacia la pared (Mecanuscrito: } \\
\text { 248) }\end{array}$ & & 338). \\
\hline $\begin{array}{l}\text { Aiguel Álvarez } z^{19} \text { dio dos } \\
\text { vueltas sobre sí mismo y } \\
\text { estuvo a punto de caerse de la } \\
\text { mesa, o cama, o lo que fuera, } \\
\text { en que le echaron } \\
\text { (Mecanuscrito: } 257 \text { ) }\end{array}$ & $\begin{array}{l}\text { Miguel Fernández dio dos } \\
\text { vueltas sobre sí mismo y } \\
\text { estuvo a punto de caerse de la } \\
\text { mesa, o cama, o lo que fuera, } \\
\text { en que le echaron. }\end{array}$ & $\begin{array}{l}\text { Miguel Fernández dio dos } \\
\text { vueltas sobre sí mismo y } \\
\text { estuvo a punto de caerse de la } \\
\text { mesa, o cama, o lo que fuera, } \\
\text { en que le echaron (2016: } 397 \text { ) }\end{array}$ \\
\hline $\begin{array}{l}\text { Porque ella no era como las } \\
\text { otras, como las que él trato, ni } \\
\text { una golfilla, ni una puta, ni una } \\
\text { de aquellas imbéciles de allá } \\
\text { arriba, "vírgenes orgullosas y } \\
\text { viciosas", que tan bien tuvo } \\
\text { ocasión de conocer. No, } \\
\text { Mónica no era ni golfa, ni } \\
\text { asustadiza, ni bien educada, ni } \\
\text { descarada. Era... "Eso era } \\
\text { cosa rara". (Mecanuscrito: 293) }\end{array}$ & [Pasaje suprimido] & [Pasaje sup \\
\hline $\begin{array}{l}\text { "¡Hijo mío...! ¡Mierda! } \\
\text { ¡Puñetera mierda!". "Mira, } \\
\text { mira; aquí, a tu hijo, comiendo } \\
\text { el arroz con pollo del día de la } \\
\text { Merced". (Mecanuscrito: } 447 \text { ) }\end{array}$ & $\begin{array}{l}\text { "Hijo mío...!". "Mira, mira; aquí, } \\
\text { a tu hijo, comiendo el arroz con } \\
\text { pollo del día de la Merced!..." }\end{array}$ & $\begin{array}{l}\text { "Hijo mío...!". "Mira, mira; aquí, } \\
\text { a tu hijo, comiendo el arroz con } \\
\text { pollo del día de la Merced!..." } \\
(2016: 600)\end{array}$ \\
\hline $\begin{array}{cl}\text { - } & \text { Calla, cabrón...calla... } \\
& \text { dijo roncamente. [...] } \\
\text { - } & \text { Que te calles, cabrón, } \\
& \text { que te calles } \\
& {[\ldots]} \\
\text { - } \quad \text { Calla, cabrón, calla... } \\
\text { (Mecanuscrito: } 496-497)\end{array}$ & $\begin{array}{ll}\text { - } & \text { Calla, } \\
& \text { imbécil...calla...- dijo } \\
& \text { roncamente. }[\ldots] \\
\text { - } & \text { Que te calles, te digo, } \\
& \text { que te calles... } \\
& {[\ldots]} \\
\text { - } & \text { Calla, animal, calla... }\end{array}$ & $\begin{array}{ll}\text { - } & \text { Calla, } \\
& \text { imbécil...calla...- dijo } \\
& \text { roncamente. }[. . .] \\
\text { - } & \text { Que te calles, te digo, } \\
& \text { que te calles... } \\
& {[\ldots]} \\
\text { - } & \text { Calla, animal, calla... } \\
& (2016: 618-619)\end{array}$ \\
\hline $\begin{array}{l}\text { - ¿Quién ha sido? } \\
\text { - El hijo de puta del } \\
\text { chico. (Mecanuscrito: } \\
500 \text { ) }\end{array}$ & $\begin{array}{ll}- & \text { ¿Quién ha sido? } \\
\text { - } & \text { El chico, es un mal } \\
\text { nacido: eso se veía de } \\
\text { lejos. }\end{array}$ & $\begin{array}{ll}- & \text { ¿Quién ha sido? } \\
\text { - } & \text { El chico, es un mal } \\
& \text { nacido: eso se veía de } \\
& \text { lejos. (2016: 622) }\end{array}$ \\
\hline $\begin{array}{l}{[\ldots] \text { en algún cabaret de }} \\
\text { maricas. (Mecanuscrito: } 577 \text { ) }\end{array}$ & $\begin{array}{l}{[\ldots] \text { en algún cabaret de poco }} \\
\text { pelo }[\ldots]\end{array}$ & $\begin{array}{l}\text { [...] en algún cabaret de poco } \\
\text { pelo [...] (2016: 693) }\end{array}$ \\
\hline $\begin{array}{l}\text { "No viven mal, esos hijos de } \\
\text { puta", pensó. (Mecanuscrito: }\end{array}$ & $\begin{array}{l}\text { «No viven mal, esos hijos...», } \\
\text { pensó. }\end{array}$ & $\begin{array}{l}\text { «No viven mal, esos hijos...», } \\
\text { pensó. (2016: 726) }\end{array}$ \\
\hline
\end{tabular}

${ }^{19}$ El nombre de Miguel Álvarez se tacha en las páginas 257, 259, 261, 284, 285, 288, 290, 291 , 298, 3008, 323, 336, 429 y 430. 


\begin{tabular}{|c|c|c|}
\hline 612) & & \\
\hline $\begin{array}{l}\text { [...] «iMai!», la llamó con una } \\
\text { voz que se notó distinta, } \\
\text { opaca. Maile rodeóla espalda } \\
\text { con los brazos y le pegó la } \\
\text { boca al oído. "No, Miguel, eso } \\
\text { no... decía- ya } \\
\text { comprendes...eso no puede } \\
\text { ser. Yo me casaré en unos } \\
\text { días... ¿sabes? } \\
\text { inevitable...otras cosas, si, si } \\
\text { quieres iQué iba a hacer! } \\
\text { pasaron el rato. Al irse el sol } \\
\text { sintieron frio. (Mecanuscrito: } \\
624 \text { ) }\end{array}$ & $\begin{array}{l}\text { «iMai!», la llamó, con una voz } \\
\text { que se notó distinta, opaca. } \\
\text { Pero Mai se estaba poniendo } \\
\text { los pendientes. Le sonreía. }\end{array}$ & $\begin{array}{l}\text { «iMai!», la llamó, con una voz } \\
\text { que se notó distinta, opaca. } \\
\text { Pero Mai se estaba poniendo } \\
\text { los pendientes. Le sonreía. } \\
\text { (2016: 736-737) }\end{array}$ \\
\hline $\begin{array}{l}\text { No puedo tardar más... "Se fue } \\
\text { a la ducha, y él encendió un } \\
\text { cigarrillo. Miró el reloj. [...] } \\
\text { Uno ve muchas cosas, a lo } \\
\text { largo de la vida. Estos no } \\
\text { están en la vida de uno. Mai } \\
\text { volvía de la ducha, fresca y } \\
\text { sonrosada, poniéndose los } \\
\text { pendientes. Le sonrió. } \\
\text { (Mecanuscrito: } 626 \text { ) }\end{array}$ & $\begin{array}{l}\text { "[...] No puedo tardar más...». } \\
\text { Miró el reloj. «[...] Uno ve } \\
\text { muchas cosas, a lo largo de la } \\
\text { vida. Éstas no están en la vida } \\
\text { de uno». }\end{array}$ & $\begin{array}{l}\text { «[...] No puedo tardar más...». } \\
\text { Miró el reloj. «[...] Uno ve } \\
\text { muchas cosas, a lo largo de la } \\
\text { vida. Éstas no están en la vida } \\
\text { de uno». (2016: 737) }\end{array}$ \\
\hline $\begin{array}{l}\text { Y se quedaron muy jodidos por } \\
\text { los japoneses } \\
\text { (Mecanuscrito: } 633 \text { ) }\end{array}$ & $\begin{array}{l}\text { Y que se quedaron muy } \\
\text { jorobados por los japoneses } \\
{[\ldots]}\end{array}$ & $\begin{array}{l}\text { Y que se quedaron muy } \\
\text { jorobados por los japoneses } \\
{[\ldots](2016: 745)}\end{array}$ \\
\hline
\end{tabular}

Las modificaciones más significativas las encontramos en los dos nombres censurados que se repiten a lo largo de la novela: López Tienda y Miguel Álvarez Pérez. En primer lugar, la autora sustituye López Tienda por Capitán Arcos. El lector tachó este nombre ya que hacía referencia al ejército republicano y lo humanizaba ${ }^{20}$. Este cambio sitúa al personaje dentro del elenco de personajes secundarios y elimina la relación emocional que el lector pueda sentir (Rotenhburg, 2021: 286). En segundo lugar, cambia Miguel Álvarez por Miguel Fernández, otro nombre cargado de significado. Según Rotehnburg (2021: 257) hace referencia al estudiante falangista, Miguel Álvarez Pérez, que resultó herido cuando volvía a casa tras un homenaje a Matías Montero - un estudiante universitario falangista asesinado en 1934 -.

20 Rafael López Tienda lideró la Columna López-Tienda o Columna de la "libertad". Esta columna estaba formada por miembros del Partido Socialista Unificado de Cataluña (PSUC) y de la Unión General de Trabajadores (UGT). López Tienda murió en otoño de 1936. 
Para finalizar, vemos como la mayoría de los pasajes tachados corresponden a palabras malsonantes y ofensivas - "puta", "jodidos", "cabrón", "mierda", "maricones" - o palabras tabúes - "guerra civil" -.

\section{Conclusiones}

Al igual que sus compañeras y compañeros de generación, Ana María Matute tuvo que someter sus obras a la tijera censora y, como hemos reflejado en el presente artículo, la incidencia de la (auto)censura en su producción literaria fue notable.

Las novelas que hemos tratado en este artículo se vieron afectadas por el lápiz rojo del censor y por la (auto)censura de la escritora y, probablemente, de los editores ${ }^{21}$. Por un lado, Luciérnagas es una novela cargada de simbolismo que refleja la censura invisible que pudo sufrir por parte de los editores y la autocensura. Asimismo, hemos expuesto cómo las similitudes y diferencias de las tres versiones de Luciérnagas evidencian la importancia de la recuperación de esta novela en una edición crítica que incluya las tres versiones (Luciérnagas 1953, En esta tierra 1955 y Luciérnagas 1993) para realizar un estudio pormenorizado de las (de)semejanzas. Por otro lado, Los Abel (1948) y Los hijos muertos (1958) ponen de manifiesto que la censura editorial sigue perpetuándose, de cierta forma, en la actualidad y, por ello, estaríamos ante una herencia cultural mutilada y silenciada.

Cuando se estudia la obra de Ana María Matute el investigador puede contar con ediciones que ofrecen un análisis exhaustivo del estilo, sus personajes, los temas, el espacio, etc. Sin embargo, en ninguna de las ediciones que hemos consultado se menciona la incidencia de la censura, ni en el prólogo ni en las notas a pie de página.

Por ello, es esencial que el filólogo en tanto que investigador y crítico literario recupere la producción literaria que tuvo lugar durante la dictadura franquista para dejar de perpetuar la (auto)censura; para que podamos leer las obras como un día fueron imaginadas por sus autoras. O, como mínimo, que contemos con un prólogo que anticipe al lector que la obra que tiene entre sus

\footnotetext{
${ }^{21}$ Soldevila (1967), Moret (2002: 83).
} 
manos está marcada por el lápiz del censor, y poder contar con una edición que coteje todas las versiones que hoy en día se conservan de una misma obra.

Para concluir, nos gustaría señalar el papel significativo que tuvo Ana María Matute dentro de la narrativa española de la posguerra. Ana María Matute transgredió el espacio femenino y se adentró en un mundo patriarcal en el que se fue consagrando como una de las mejores escritoras del siglo pasado. Como hemos visto, los temas de sus novelas no siguen los estereotipos marcados por el régimen franquista y sus protagonistas suelen ser niñas diferentes al resto, chicas "raras". Además, sus novelas, aunque tienen como telón de fondo la guerra civil, no tienen un objetivo ideológico sino de denuncia social ante las injusticias que experimentó. A través de la mirada infantil e inocente se presenta el conflicto bélico y el posterior desencanto cuando los personajes alcanzan la edad adulta.

\section{Bibliografía}

Abellán, M. (1980). Censura y creación literaria en España (1939-1976). Barcelona: Península.

ALDECOA, Josefina (1983). Los niños de la guerra. Madrid: Ediciones generales Anaya.

Alted VigiL, Alicia (1991). "Las mujeres en la sociedad española de los años cuarenta" en Las mujeres y la guerra civil española. Salamanca: Ed. Ministerio de Trabajo e inmigración, Instituto de la Mujer.

ESTRUCH TOBELLA, Joan (2014). "Las tres versiones de "Luciérnagas", de Ana María Matute". Ínsula: revista de letras y ciencias humanas, n.ㅇ 815, pp. 16.

FERRERAS, Juan Ignacio (1988). La novela en el siglo XX. Madrid: Taurus.

GazArian-Gautier M.L (1997). Ana María Matute: La voz del silencio. Madrid: Espasa Calpe.

LARRAZ, Fernando (2014). Censura y novela durante el franquismo. Gijón: Trea. MARTín GAITE, Carmen (1994). Usos amorosos de la posguerra española. Barcelona: Anagrama.

MARTíneZ MARTín, Jesús A. (dir.) (2015). Historia de la edición en España 19391975. Madrid: Marcial Pons Historia.

Matute, AnA María (1948). Los Abel. Barcelona: Destino.

MATUTE, ANA MARÍA (1955). En esta tierra. Barcelona: Planeta.

MATUTE, ANA María [1948] (2015). Los Abel. Barcelona: Planeta.

MATUTE, ANA MARía [1958] (2015). Los hijos muertos. Barcelona: Planeta.

MATUTE, ANA María [1958] (2016). Los hijos muertos. Edición de José Más y M.a Teresa Mateu. Madrid: Cátedra.

Matute, Ana María [1993] (2019). Luciérnagas. Edición de María Luisa Sotelo 
Vázquez. Madrid: Cátedra.

MONTEJO GURRUCHAGA, Lucía (2010). Discurso de autora: género y censura en la narrativa española de posguerra. Madrid: UNED.

MORET, Xavier (1993). "Matute recupera "Luciérnagas», una novela de niños marcados por la guerra", El País, 27-octubre, en https://elpais.com/diario/1993/10/27/cultura/751676405 850215.html [Fecha de consulta: 15 de mayo de 2021].

MoRet, XaVIER (2002). Tiempo de editores. Historia de la Edición en España, 1939-1975. Barcelona: Destino.

PueYo DOLADER, Olga (2019). "Secuelas y epílogos de la censura editorial. El caso de Gabriel García Badell”, Represura Nueva Época, n. 4, pp. 3970.

RotehnbuRg, Anja (2021). Literatur in der Diktatur - Diktatur in der Literatur. Einfluss und Auswirkungen franquistischer Zensur auf das Werk von Ana María Matute. (Tesis doctoral). Humboldt Universität, Berlín.

SANTAMARIA, Sara (2020). La querella de los novelistas. La lucha por la memoria en la literatura española (1990-2010). Valencia: Publicacions de la Universitat de València.

SARLO, Beatriz (2000). El imperio de los sentimientos. Buenos Aires: Norma.

SOLDEVILA DURANTE, Ignacio (1967). "La novela española actual. Tentativa de entendimiento", Revista Hispánica moderna, n.ำ1-2, pp. 89-108.

SOLDEVILA DURANTE, Ignacio (1980). La novela española desde 1936. Madrid: Alhambra.

TORTOSA, Virgilio (2014) "El "Ángel de la Historia" en la memoria literaria del franquismo". Memoria y poéticas de una Europa en Guerra, 1936-1945. Alicante: Biblioteca Virtual Miguel de Cervantes, pp. 63-84. En http://www.cervantesvirtual.com/obra/memoria-y-poeticas-de-unaeuropa-en-guerra-1936-1945/ [Fecha de consulta: 15 de mayo de 2021].

Fecha de recepción: 15 de septiembre de 2021

Fecha de aceptación: 9 de diciembre de 2021 